\title{
Insurance Status and Biological and Psychosocial Determinants of Cardiometabolic Risk Among Mexican-Origin U.S. Hispanic/Latino Adults with Type 2 Diabetes
}

Namino M. Glantz, ${ }^{1, *}$ Jessikah M. Morales, ${ }^{1}$ Wendy C. Bevier, ${ }^{1}$ Arianna Larez, ${ }^{1}$ Charis B. Hoppe, ${ }^{1}$ Ian Duncan, ${ }^{2}$ Andrew Mackenzie, ${ }^{3}$ and David Kerr ${ }^{1}$

\begin{abstract}
Purpose: Hispanics/Latinos in the United States bear higher burden of type 2 diabetes (T2D) and associated complications compared with the general population. Health insurance coverage is also lower in this population. We examined the association of health insurance with biological and psychosocial determinants of cardiometabolic risk among U.S. Mexican-origin Hispanic/Latino adults with T2D.

Methods: Participants were self-reported Hispanic/Latino adults with T2D diagnosis. Trained bilingual community health workers collected cross-sectional information on biological and psychosocial factors using clinical examinations, laboratory tests, validated questionnaires, and wearable activity monitors.

Results: One hundred and seven Hispanic/Latino adults (54 12 years, 65\% female, 36\% prescribed insulin, 60\% uninsured) with T2D were enrolled. While 93\% had low language-based acculturation, $88 \%$ had high health literacy in Spanish. Forty percent were food insecure and $47 \%$ expressed at least one social need. Overall, 35\% had an $\mathrm{HbA}_{1 c}<7.0 \%$ (indicating good control) and $31 \%$ had an $\mathrm{HbA}_{1 c}>9.0 \%$. Sixty-three percent had blood pressure within target $(<130 / 80 \mathrm{mmHg}$ ), and overall participants were moderately physically active. However, 53\% were obese (body mass index $\geq 30 \mathrm{~kg} / \mathrm{m}^{2}$ ) and $76 \%$ had a waist measurement defined as high risk ( $>88 \mathrm{~cm}$ for women and $>102 \mathrm{~cm}$ for men). Participants without health insurance were younger (51.9 \pm 10.4 vs. $58.8 \pm 10.5$ years mean \pm standard deviation, $p=0.0008)$ but had higher $\mathrm{HbA}_{1 \mathrm{c}}(8.4 \pm 2.2 \%$ vs. $7.6 \pm 1.6, p=0.031)$ and fasting glucose (184.9 \pm 86.5 vs. $148.6 \pm 61.2 \mathrm{mg} / \mathrm{dl}, p=0.008)$ levels.

Conclusions: Health insurance status appears to influence achieved glycemic control for U.S. Hispanic/Latino adults with T2D. However, various psychosocial factors potentially influencing cardiometabolic risk independently of health insurance status may also be implicated in the inequitable burden of T2D. ClinicalTrials.gov Identifier: NCT03736486.
\end{abstract}

Keywords: Hispanic; Latino; diabetes; cardiometabolic risk; health insurance

\section{Introduction}

In the United States, racial and ethnic minority groups are disproportionally impacted by diabetes, especially type 2 diabetes (T2D). The prevalence of diagnosed and undiagnosed T2D among Mexican-origin Hispanic/
Latino adults is nearly double that in non-Hispanic white adults. ${ }^{1}$ Furthermore, rates of diabetes-related complications, including premature death, acute stroke, and end-stage renal disease, are higher among Hispanic/ Latino adults than non-Hispanic whites. ${ }^{2}$ Additional

\footnotetext{
1 Sansum Diabetes Research Institute, Santa Barbara, California, USA.

${ }^{2}$ Department of Statistics and Applied Probability, University of California Santa Barbara, Santa Barbara, California, USA
}

${ }^{3}$ Santa Barbara Actuaries, Santa Barbara, California, USA.

*Address correspondence to: Namino M. Glantz, PhD, Sansum Diabetes Research Institute, 2219 Bath Street, Santa Barbara, CA 93103, USA, E-mail: nglantz@sansum.org

(c) Namino M. Glantz et al. 2020; Published by Mary Ann Liebert, Inc. This Open Access article is distributed under the terms of the Creative Commons License (http://creativecommons.org/licenses/by/4.0), which permits unrestricted use, distribution, and reproduction in any medium, provided the original work is properly cited. 
concerns are worsening rates of detection of previously undiagnosed T2D among Hispanic/Latino adults versus non-Hispanic white, very high income, and older adults. ${ }^{3}$

Among established clinical drivers of excess T2D burden on the U.S. Hispanic/Latino population are delays in diabetes diagnosis, ${ }^{4}$ suboptimal blood glucose control, and low rates and frequency of self-monitoring and screening for complications. ${ }^{5-7}$ Beyond biological factors, such as $\mathrm{HbA}_{1 \mathrm{c}}$, sociocultural influences are also important determinants of T2D risk. These include ethnicity (e.g., greater T2D burden in Mexican Americans than Cuban Americans), acculturation, education, economic status, and residence. ${ }^{8,9}$ Another potentially relevant factor is access to health insurance. In the United States, lack of health insurance influences access to and participation in treatment plans for diabetes diagnosis, self-management, and use of timely and appropriate therapies. ${ }^{10}$ In turn, health insurance status may impact both clinical determinants (e.g., $\mathrm{HbA}_{1 c}$ ) and psychosocial determinants (e.g., stress) of health, and influence ability to reduce personal diabetes risk.

Nationally, U.S. Hispanic/Latino individuals are disproportionately affected by lack of health insurance. ${ }^{11}$ Furthermore, racial and ethnic disparities exist in the burden and cost of diabetes care even for those with health insurance. ${ }^{12}$ Among Hispanic/Latino individuals with diabetes, those lacking health insurance have higher rates of microvascular complications. ${ }^{13}$ Thus, expanding health insurance access has been suggested as having potential to eliminate health disparities among Hispanic/Latino populations. The aim of this study was to determine whether there is a relationship between health insurance coverage and biological and psychosocial determinants of health among Hispanic/Latino adults with T2D in a California Central Coast community in which Hispanic/Latinos comprise $45 \%$ of the population, most of Mexican origin. ${ }^{14}$

\section{Methods}

The study was approved by an independent review board (Quorum 32669/1). Eligible participants were of self-reported Hispanic/Latino heritage, aged $\geq 18$ years with a $\geq 1$ year T2D diagnosis. Individuals were excluded if they self-reported a diagnosis of severe cardiovascular disease within the prior 6 months limiting their ability to attend study visits, a likelihood of $<2$ years life expectancy, and/or participation in other trials involving medication or device/s within the prior month.

\section{Recruitment and consent}

Participants were recruited through existing Sansum Diabetes Research Institute (SDRI) and community outreach and service programs as well as a local federally qualified health center (FQHC) that provides safety net care to Hispanic/Latino families. Individuals amenable to sharing their contact information were referred to trained bilingual community health workers known as Especialistas, who provided IRB-approved verbal and printed information about study aims and requirements. Especialistas then facilitated informed consent with those interested in participating.

All study materials were available in English and Spanish, and activities were conducted in the participant-preferred language/s. Validated questionnaires were approved for translation by the original authors and translated through certified translation services. Especialistas reviewed methods and materials for cultural congruence.

\section{Participant activities}

Once consented, participants completed a study visit series for data collection. Biological data were captured through a clinical examination by a medically qualified provider at the FQHC and a blood draw at a partnering laboratory. At SDRI, Especialistas collected psychosocial and behavioral data by applying validated questionnaires and wearable activity monitors. Participants completed visit activities in the following order:

(1) Consent, enrollment, questionnaires

(2) Laboratory analyses

(3) Physical examinations

(4) Wearable activity monitoring, questionnaires.

(5) Conclusion

On average, participants completed visits pertinent here (1-4) within 6 months of enrollment (minimum 3 , maximum 11, median 4 months).

At Visit 1, after consent, Especialistas collected sociodemographic information, including health insurance status, household size, educational attainment, and employment, using an SDRI-developed Introductory Interview (II). Participants next answered brief openended questions about diabetes in their family, their perceptions of what diabetes is, why it is common in Hispanic/Latino families, and how to prevent and address it. Participants then completed three questionnaires validated in Hispanic/Latino populations. The 6-item U.S. Household Food Security Survey Module short form (HFSSM) produces a score of high, marginal, 
low, or very low food security. ${ }^{15}$ The Social Needs Screening (SNS) is a 9-item questionnaire with "yes" or "no" answers regarding common social determinants of health across five domains: utilities, housing, childcare, health care, and domestic violence. ${ }^{16-18}$ The brief Perceived Self-Assessment of Diabetes Management (PSADM) probes support, dietary behavior, learning style, cultural and religious practices, and handling stress, using 10 multiple-choice and shortanswer questions. ${ }^{19}$

At Visit 2, participants were asked to arrive fasting unless insulin treated. A blood draw was collected for $\mathrm{HbA}_{1 \mathrm{c}}$, complete metabolic and lipid panel, full blood count, thyroid function, and insulin levels (for noninsulin users). Laboratory analysis was completed by a commercial laboratory in partnership with the FQHC. Results were accessed through secure patient electronic medical records. Homeostatic model assessment for insulin resistance (HOMA-IR) was calculated as HOMAIR score $=$ fasting insulin $(\mu \mathrm{IU} / \mathrm{mL}$ or $\mathrm{mU} / \mathrm{L}) \times$ fasting glucose $(\mathrm{mg} / \mathrm{dL}) / 405 .^{20}$

At Visit 3, an FQHC provider recorded medical history and medications; performed a physical examination (including height, weight, and waist circumference); and screened for common diabetes-related complications (e.g., eye, kidney, nerve, and circulation damage). Relative fat mass (RFM) was calculated by the Woolcott and Bergman 2018 method. ${ }^{21}$ The 9-item Likert scale Patient Health Questionnaire-9 (PHQ-9) was applied to screen for depression. ${ }^{22}$

Subsequently, at Visit 4, participants met with Especialistas to complete additional psychosocial questionnaires validated in Hispanic/Latino populations. The Oviedo Sleep Questionnaire (OSQ) uses 11 Likert scale items to assess subjective sleep quality, insomnia, hypersomnia, and use of sleep aids. ${ }^{23,24}$ The Perceived Stress Scale (PSS-4) evaluates frequency of stress over the previous month using 4-item Likert scale; scoring yields low or high stress ratings. ${ }^{25}$ The Perceived Ethnic Discrimination Questionnaire-Community Version (PEDQ-CV) consists of 17 Likert-scaled questions to assess frequency of discrimination based on ethnicity to yield subscale scores for exclusion/rejection, stigmatization/devaluation, threat/aggression, and discrimination at work or school, and lifetime exposure to discrimination. ${ }^{26}$ The 4-item Likert-scaled Brief Acculturation Scale for Hispanics (BASH) probes comfort with English and Spanish language use as a proxy for low and high acculturation. ${ }^{27}$ Finally, the Short Assessment of Health Literacy (SAHL) is an 18-item exercise to assess ability to read and understand common medical terms in the participant's preferred language (predominantly Spanish). ${ }^{28}$ Participants were shown flashcards that contain three words, and were asked to identify the correct synonym to the first word on the card; scoring indicated low or high health literacy.

Participants were then provided with two wearable physical activity monitors: an ActiGraph wGT3X-BT (ActiGraph, LLC, Pensacola, FL) worn around the waist on the dominant hip, and a Fitbit Charge $2^{\mathrm{TM}}$ (Fitbit, Inc., San Francisco, CA) worn on the nondominant wrist. Especialistas trained participants on wearable device use and care, instructing them to wear the devices for at least 6 days and nights, removing them only for bathing or swimming. After a week, participants returned both devices to SDRI.

Finally, Visit 5, dedicated to closing out the visit series, took place at least 1 week after Visit 4 . In this visit, Especialistas applied SDRI-developed questionnaires to capture information on participant experience in the study.

Perceptions of the meaning of disease are influential in health outcomes, with favorable illness perception associated with better health outcomes, and unfavorable perception associated with worse outcomes. ${ }^{29,30}$ To explore this possibility, we went beyond biological descriptors and quantitative psychosocial metrics (e.g., achieved $\mathrm{HbA}_{1 \mathrm{c}}$, weight, insulin use, and depression) to explore qualitative perceptions of diabetes. Specifically, two independent bilingual raters conducted thematic analysis of answers to the question, "In your own words, what is diabetes?" This yielded five categories: controllable, sugar, body malfunction, illness, doom/death. ${ }^{31}$ Doom/death was a prominent theme in participant definitions of diabetes, with participants using words such as bad, sad, serious, degenerative, incurable, torturous, lifelong, and deadly.

\section{Statistical analyses}

Means and standard deviation (SD) were calculated for all variables except steps per weekday and weekend. The Shapiro-Wilk test showed that accelerometer values were not normally distributed; therefore, median and range were calculated for steps per day. Betweengroup comparisons were made using a Welch's $t$-test. Additional comparisons of proportions were made using the chi-squared test. Significance thresholds were 
set at the 95\% level. Differences for steps per day for weekdays and weekends were compared using MannWhitney $U$ tests between insured versus uninsured.

To probe possible generalizability and transferability of methods and findings from this pilot sample to larger populations, results were compared with those of a large established cohort. ${ }^{32,33}$ The Hispanic Community Health Study/Study of Latinos (HCHS/SOL) is a community-based cohort study of 16,415 selfidentified Hispanic/Latino adults, of which 2148 individuals self-reported a diagnosis of diabetes, and of whom 856 self-identified as of Mexican heritage.

\section{Results}

Between September 2017 and August 2018, 107 Hispanic/Latino adults with T2D (95\% of Mexican heritage, $67 \%$ female) provided written informed consent and enrolled in the study. Participant activities culminated in October 2018. Nearly all participants (98\%) opted to use Spanish (over English) study materials. All variables reported in this study were collected (in Visits 1-4) from $50 \%$ of participants within 3 months of enrollment, and from $90 \%$ of participants within 6 months of enrollment (median 4 months).

\section{Insurance status}

Of 101 participants reporting their current health insurance status, $61(60 \%)$ had no insurance and 40 (40\%) had insurance at study initiation. Among the 40 participants who were insured upon enrollment, the majority (31) were covered by a Medi-Cal plan.

\section{Biological and behavioral determinants and health insurance status}

At enrollment, $36 \%$ of participants had been prescribed insulin, $46 \%$ a statin, and $31 \%$ blood pressure lowering medication. Thirty-five percent had an $\mathrm{HbA}_{1 \mathrm{c}}<7.0 \%$ and $31 \%$ had an $\mathrm{HbAl}_{\mathrm{c}}>9.0 \%$. More than half $(63 \%)$ of participants had blood pressure $<130 / 80 \mathrm{mmHg}$. Based on body mass index (BMI) criteria, $12 \%$ of subjects had a normal value $\left(18.5-24.9 \mathrm{~kg} / \mathrm{m}^{2}\right)$, whereas $53 \%$ were in the obese range (BMI $\geq 30 \mathrm{~kg} / \mathrm{m}^{2}$ ). Three-quarters $(76 \%)$ of overall participants had a waist measurement defined as high risk $(>88 \mathrm{~cm}$ for women and $>102 \mathrm{~cm}$ for men), with an average measurement of $103.8 \pm 13.5 \mathrm{~cm}$ (mean \pm SD) among women and $105.1 \pm 12.6 \mathrm{~cm}$ among men. ${ }^{34}$
Table 1. Biometric Descriptors by Health Insurance Status (Mean \pm Standard Deviation)

\begin{tabular}{lccc}
\hline Biometric & Uninsured & Insured & $p$ \\
\hline Age (in years) & $51.9 \pm 10.4$ & $58.8 \pm 10.5$ & 0.0008 \\
HbA $_{1 \mathrm{c}}(\%)$ & $8.4 \pm 2.2$ & $7.6 \pm 1.6$ & 0.0307 \\
Fasting glucose (mg/dL) & $184.9 \pm 86.5$ & $148.6 \pm 61.2$ & 0.0079 \\
Waist circumference (cm) & $101.9 \pm 10.5$ & $108.7 \pm 16.3$ & 0.0223 \\
Waist circumference (female) & $102.1 \pm 11.8$ & $106.9 \pm 16.0$ & $\mathrm{NS}$ \\
Waist circumference (male) & $101.7 \pm 7.9$ & $111.7 \pm 17.1$ & $\mathrm{NS}$ \\
Systolic blood pressure $(\mathrm{mmHg})$ & $123.1 \pm 17.1$ & $128.4 \pm 15.5$ & $\mathrm{NS}$ \\
Body mass index $\left(\mathrm{kg} / \mathrm{m}^{2}\right)$ & $30.8 \pm 6.0$ & $32.8 \pm 6.4$ & $\mathrm{NS}$ \\
Weight (kg) & $76.9 \pm 15.7$ & $83.4 \pm 19.7$ & $\mathrm{NS}$ \\
Relative fat mass & $40.2 \pm 7.7$ & $41.8 \pm 8.1$ & $\mathrm{NS}$ \\
HOMA-IR & $4.8 \pm 2.2$ & $4.6 \pm 2.2$ & $\mathrm{NS}$ \\
LDL cholesterol $(\mathrm{mg} / \mathrm{dL})$ & $97.5 \pm 35.1$ & $101.3 \pm 28.3$ & $\mathrm{NS}$ \\
Total cholesterol $(\mathrm{mg} / \mathrm{dL})$ & $183.5 \pm 57.3$ & $179.4 \pm 39.6$ & $\mathrm{NS}$ \\
Triglycerides $(\mathrm{mg} / \mathrm{dL})$ & $170.7 \pm 111.3$ & $166.7 \pm 112.7$ & $\mathrm{NS}$ \\
& & &
\end{tabular}

HOMA-IR, homeostatic model assessment for insulin resistance; LDL, low-density lipoprotein; NS, not significant.

Table 1 displays participant biometrics stratified by insurance status. Of these 12 different biological determinants, 4 significantly differed by insurance status:

- Uninsured participants were younger than insured participants.

- Uninsured participants had higher $\mathrm{HbA}_{1 \mathrm{c}}$ than insured participants.

- Uninsured participants had higher fasting glucose than insured participants.

- Uninsured participants had a smaller waist circumference than insured participants.

Overall, ActiGraph and Fitbit showed moderate physical activity levels (Table 2). However, the average step count per day reported by ActiGraph was significantly lower compared with Fitbit (median [range] 7145.8 [1953.3-18,668.3] vs. 8674.7 [1946.7-24,544.3]; $[p<0.05])$. There was a significant difference between uninsured and insured for average steps per day and average steps per weekday measured by ActiGraph, with the uninsured showing more activity than the insured. No significant differences were seen for average steps per weekend, or for steps per day, weekday, or weekend measured by Fitbit.

\section{Psychosocial determinants and health}

insurance status

In general, participants were $<65$ years of age (84\%), with most living in $3+$ person households (78\%). Forty percent reported food insecurity. More than half had less than a high school education (55\%) and were unemployed (57\%). Nearly half (47\%) 
Table 2. Average Step Counts per Day Assessed by ActiGraph and Fitbit for Weekdays, Weekends, and All Days of the Week by Health Insurance Status

\begin{tabular}{lcc}
\hline & & Median (range) \\
\cline { 3 - 3 } Device and day type & Uninsured & Insured \\
\hline ActiGraph measured average steps/weekday & $7945.6(3880.5-19,481.3)$ & $6193.0(1840.3-18,423.6)$ \\
ActiGraph measured average steps/weekend & $7083.5(1543.0-18,375.0)$ & $5256.0(1560.5-19,892.0)$ \\
ActiGraph measured average steps per day & $7368.1(3734.3-15,310.6)$ & $5770.2(1953.3-18,668.3)$ \\
Fitbit measured average steps/weekday & $8654.0(1174.2-24,561.3)$ & $9828.4(1171.8-21,223.0)$ \\
Fitbit measured average steps/weekend & $7675.5(3172.5-20,855.0)$ & $6674.5(1775.5-18,235.0)$ \\
Fitbit measured average steps per day & $8644.5(1946.7-24,544.3)$ & NS \\
\hline
\end{tabular}

Significance was measured using Mann-Whitney U tests.

expressed at least one social need (utilities, housing, childcare, health care, and/or domestic violence). Nearly all (94\%) had immigrated to the United States, primarily from Mexico. Most had low language-based acculturation (93\%), but high health literacy in Spanish $(88 \%)$. The majority indicated sleep satisfaction (60\%), no depression (72\%), and low stress (78\%).

Table 3 displays psychosocial determinants stratified by insurance status. Of these 12 psychosocial factors, 3 significantly differed by insurance status:

- Uninsured participants were younger than insured participants.

- Uninsured participants lived in larger households than insured participants.

- Uninsured participants were more food secure than insured participants.

When stratified by insurance status, there was no significant difference between uninsured and insured participant likelihood to define diabetes as doom/death.

\section{Comparison with $\mathrm{HCHS} / \mathrm{SOL}$}

To probe generalizability and transferability from this pilot sample to larger populations, we compared our results with those of the large established cohort of Hispanic/Latino adults with T2D from the HCHS/SOL. ${ }^{33}$ Comparisons of biological determinants between our study population and the 856 total HCHS/SOL participants of Mexican heritage with T2D are shown in Table 4. In general, in terms of age, $\mathrm{HbA}_{1 \mathrm{c}}$, waist circumference, blood pressure, BMI, and low-density lipoprotein cholesterol, the two cohorts appear to be similar.

The HCHS/SOL included few psychosocial variables similar to this study. Two psychosocial areas in which comparisons could be made are depression and social needs. In our study of Hispanic/Latinos predominantly of Mexican origin, the rate of depression was $28 \%$, which is similar to the rate in the HCHS/SOL cohort of Hispanic/Latino adults of any origin (27\%), but higher than the rate among HCHS/SOL participants of Mexican origin (22\%). ${ }^{35}$ In terms of social needs, in our study, the most prominent need was "could not see a physician because of cost" (13\%). Among Table 3. Psychosocial Determinants of Health
by Health Insurance Status

\begin{tabular}{|c|c|c|c|}
\hline Determinant & Uninsured \% & Insured \% & $\chi^{2}$ \\
\hline \multicolumn{4}{|l|}{ Age (years) } \\
\hline$<65$ & 90.1 & 75.0 & \multirow[t]{2}{*}{$4.17^{\mathrm{a}}$} \\
\hline$\geq 65$ & 9.8 & 25.0 & \\
\hline \multicolumn{4}{|l|}{ Household size } \\
\hline 1-2 Person household & 13.1 & 37.5 & \multirow[t]{2}{*}{$8.17^{\mathrm{a}}$} \\
\hline $3+$ Person household & 86.9 & 62.5 & \\
\hline \multicolumn{4}{|l|}{ Food security } \\
\hline Low food security & 31.1 & 55.0 & \multirow[t]{2}{*}{$5.70^{\mathrm{a}}$} \\
\hline High food security & 68.9 & 45.0 & \\
\hline \multicolumn{4}{|l|}{ Education } \\
\hline Less than high school & 59.6 & 57.9 & \multirow[t]{2}{*}{ NS } \\
\hline High school or more & 40.4 & 42.1 & \\
\hline \multicolumn{4}{|l|}{ Employment status } \\
\hline Unemployed & 57.4 & 57.5 & \multirow[t]{2}{*}{ NS } \\
\hline Employed & 42.6 & 42.5 & \\
\hline \multicolumn{4}{|l|}{ Social needs } \\
\hline 0 Social needs & 47.5 & 57.5 & \multirow[t]{2}{*}{ NS } \\
\hline 1 or More social needs & 52.5 & 42.5 & \\
\hline \multicolumn{3}{|l|}{ Immigrated to the United States } & \multirow[t]{3}{*}{ NS } \\
\hline No & 4.9 & 7.5 & \\
\hline Yes & 95.1 & 92.5 & \\
\hline \multicolumn{4}{|l|}{ Acculturation } \\
\hline Low acculturation & 92.7 & 94.4 & \multirow[t]{2}{*}{ NS } \\
\hline High acculturation & 7.3 & 5.6 & \\
\hline \multicolumn{4}{|l|}{ Health literacy } \\
\hline Low health literacy & 14.6 & 8.3 & \multirow[t]{2}{*}{ NS } \\
\hline High health literacy & 85.4 & 91.7 & \\
\hline \multicolumn{4}{|l|}{ Sleep satisfaction } \\
\hline Very satisfied/satisfied & 60.0 & 58.3 & \multirow[t]{2}{*}{ NS } \\
\hline Dissatisfied & 40.0 & 41.7 & \\
\hline \multicolumn{4}{|l|}{ Depression } \\
\hline No depression & 72.0 & 72.7 & \multirow[t]{2}{*}{ NS } \\
\hline Depression & 28.0 & 27.3 & \\
\hline \multicolumn{4}{|l|}{ Perceived stress } \\
\hline Low stress & 72.7 & 86.1 & \multirow[t]{2}{*}{ NS } \\
\hline High stress & 27.3 & 13.9 & \\
\hline
\end{tabular}

${ }^{\mathrm{a}} p<0.05$ comparing uninsured with insured. 
Table 4. Comparison of Biological Determinants in Current Cohort with the Hispanic Community Health Study/Study of Latinos Cohort

\begin{tabular}{lcc}
\hline Determinant & $\begin{array}{c}\text { Current } \\
\text { cohort } \\
(\boldsymbol{n}=107) \\
\text { Percentage }\end{array}$ & $\begin{array}{c}\text { HCHS/SOL cohort: } \\
\text { Mexican adults } \\
\text { with T2D }(\boldsymbol{n}=856) \\
\text { Percentage }\end{array}$ \\
\hline Age (years) & & \\
$22-39$ & 10.3 & 19.0 \\
$40-59$ & 58.9 & 51.9 \\
$60-80$ & 30.8 & 29.1 \\
$\mathrm{HbA}_{1 \mathrm{c}}<7.0 \%$ & 35.6 & 41.6 \\
$\mathrm{HbA}_{1 \mathrm{c}} \geq 9.0 \%$ & 30.7 & 31.4 \\
$\mathrm{High}$ risk waist circumference, & 76.0 & 70.0 \\
$>88 \mathrm{~cm}$ women, $>102 \mathrm{~cm}$ men & & \\
Blood pressure $>130 / 80 \mathrm{mmHg}$ & 41.0 & 41.0 \\
Body mass index, kg/m 2 & & \\
$18.5-24.9$ & 11.8 & 10.4 \\
$25.0-29.9$ & 34.4 & 35.7 \\
$30.0-34.9$ & 30.1 & 30.0 \\
$\geq 35.0$ & 22.6 & 23.9 \\
LDL-cholesterol $>100 \mathrm{mg} / \mathrm{dL}$ & 45.0 & 62.0 \\
\hline
\end{tabular}

$\mathrm{HCHS} / \mathrm{SOL}$, Hispanic Community Health Study/Study of Latinos; T2D, type 2 diabetes.

the Mexican participants with diabetes in the HCHS/ SOL, nearly $15 \%$ had needed health care in the past 12 months but could not get it. ${ }^{33}$

\section{Discussion}

In the United States, the Hispanic/Latino population is the fastest growing ethnic minority group and is known to have an excess burden of diabetes and associated complications compared with the general population. ${ }^{1}$ Health insurance coverage has been cited as a factor in diabetes diagnosis, self-management, use of timely and appropriate therapies, and, ultimately, clinical health outcomes for the general population. ${ }^{10}$ In this study, we examined the association of health insurance status with biological and psychosocial determinants of health for U.S. Hispanic/Latino adults, predominantly of Mexican origin, with an established diagnosis of T2D.

Of 12 biological determinants of health assessed in this study, 4 differed significantly by insurance status: age, $\mathrm{HbA}_{1 \mathrm{c}}$, fasting glucose, and waist circumference. Notably, from a purely glycemic perspective, having health insurance was associated with better glycemic control. However, both insured and uninsured groups had unfavorable cardiovascular risk profiles with high rates of hyperlipidemia, obesity, insulin resistance, and excess levels of high-risk waist measurements, although average waist circumference was significantly higher among the insured group. This clinical profile indicates a population in poor health and at risk for complications stemming from inadequate diabetes management, regardless of insurance status.

Accelerometer and consumer device measured physical activity assessment suggested fairly high levels of physical activity in this study population, regardless of insurance status and consistent with previous data. ${ }^{36}$ Overall, insured and uninsured participants alike came close to or met the recommended 10,000 daily steps. ${ }^{37}$ Furthermore, we detected consistent differences between step counts recorded by both devices during the week compared with weekends. ${ }^{38}$ ActiGraph captured significantly higher average steps per day and average steps per weekday among uninsured participants than insured participants. Both physical activity rates and insurance status may be independently associated with occupation.

Two of the 12 psychosocial determinants of health assessed in this study were associated with having health insurance: living in a smaller household and food insecurity. It may be that people must choose to invest in either insurance or food, and/or that people with low income without health insurance qualify for food benefits (e.g., Supplemental Nutrition Assistance Program), whereas employed insured people earn too much to qualify for benefits yet not enough to purchase adequate food. Regardless of insurance status, we found high rates of health literacy and sleep satisfaction, and low rates of depression and stress, which may contrast with the larger U.S. population with T2D, and may be potentially advantageous to this Hispanic/Latino, predominantly Mexican-origin subpopulation.

Finally, we compared the overall study population with a larger cohort of Hispanic/Latino adults with T2D cohort published previously. ${ }^{30}$ We confirmed various biological similarities as well as indication of various psychosocial similarities between the two samples.

\section{Limitations}

Untangling the association between and potential influence of T2D status on access to health insurance-and conversely the impact of insurance status on diabetes outcomes-is challenging. The relatively small sample size, gender division of the sample, and geography from which the sample was obtained limit interpretation of the findings. In addition, the heritage of participants was overwhelmingly Mexican and thus findings may not be applicable to non-Mexican-origin groups comprising the wider Hispanic/Latino population. Data were collected for 4-6 months, during which time insurance status, biological, behavioral, and 
psychosocial variables may have changed. There are also probable biases between the risk profiles of the insured compared with uninsured populations in this study. It is possible that individuals without insurance might be at higher risk because they do not have sufficient access to preventative and maintenance treatments and medical care. However, it is also possible that Hispanic/Latinos with health insurance might be at higher risk because of more health concerns and thus be more likely to purchase health insurance than those with fewer health issues that require maintenance treatment. There is some evidence to support the latter scenario, as the insured group was older and had a larger waist measurement, as well as a tendency for higher systolic blood pressure and BMI, compared with the uninsured group.

\section{Conclusions and Health Equity Implications}

In conclusion, contrary to the prevalent and often evidence-based assertion that health insurance is an impactful determinant of diabetes outcomes, we did not find many associations between health insurance and the biological and psychosocial metrics assessed in this sample of Hispanic/Latino adults with T2D, most of Mexican origin. This underscores the need to assess the relationship between myriad biological and psychosocial factors and T2D in U.S. subpopulations. ${ }^{39}$ The similarities between characteristics in our cohort and the larger nationwide HCHS/SOL cohort suggest that our findings in this small localized community in the California Central Coast may be representative of Hispanic/Latino populations nationwide. The contrast between both Hispanic/Latino cohorts and the general population evidences the need to explore in subpopulations the role of health insurance alongside biological and other psychosocial determinants, such as food security and social support, known to impact diabetes self-management in underserved populations with T2D. ${ }^{40-42}$

\section{Acknowledgments}

The authors thank Dr. Charles Fenzi and the staff at Santa Barbara Neighborhood Clinics for their help with this project.

\section{Author Disclosure Statement}

N.M.G., J.M.M., W.C.B., A.L., and D.K. are employees of SDRI. C.B.H. was an employee at SDRI at the time the study was being conducted. D.K. has received honoraria for participation in advisory boards for Novo
Nordisk, Sanofi, and Ascensia and is a medical advisor to Glooko and Vicentra. A.M. and I.D. are employees of Santa Barbara Actuaries.

\section{Funding Information}

The study was funded by an unrestricted grant from Eli Lilly and Company.

\section{References}

1. National Center for Health Statistics. Health, United States, 2016: With Chartbook on Long-Term Trends in Health. Hyattsville, MD: National Center for Health Statistics (US), 2017.

2. Golden $\mathrm{SH}$, Brown A, Cauley JA, et al. Health disparities in endocrine disorders: biological, clinical, and nonclinical factors-an Endocrine Society scientific statement. J Clin Endocrinol Metab. 2012;97:E1579-E1639.

3. Geiss LS, Bullard KM, Brinks R, et al. Trends in type 2 diabetes detection among adults in the USA, 1999-2014. BMJ Open Diabetes Res Care. 2018; 6:e000487.

4. Fisher-Hoch SP, Vatcheva KP, Rahbar MH, et al. Undiagnosed diabetes and pre-diabetes in health disparities. PLoS One. 2015;10:e0133135.

5. Campbell JA, Walker RJ, Smalls BL, et al. Glucose control in diabetes: the impact of racial differences on monitoring and outcomes. Endocrine. 2012;42:471-482.

6. Kirk JK, Passmore LV, Bell RA, et al. Disparities in A1c levels between Hispanic and non-Hispanic white adults with diabetes: a meta-analysis. Diabetes Care. 2008;31:240-246

7. Canedo JR, Miller ST, Schlundt D, et al. Racial/ethnic disparities in diabetes quality of care: the role of healthcare access and socioeconomic status. J Racial Ethn Health Disparities. 2018;5:7-14.

8. Aviles-Santa ML, Colon-Ramos U, Lindberg NM, et al. From sea to shining sea and the Great Plains to Patagonia: a review on current knowledge of diabetes mellitus in Hispanics/Latinos in the US and Latin America. Front Endocrinol (Lausanne). 2017;8:298.

9. Beydoun MA, Beydoun HA, Mode N, et al. Racial disparities in adult allcause and cause-specific mortality among us adults: mediating and moderating factors. BMC Public Health. 2016;16:111-113.

10. McGinley EL, Gabbay RA. The impact of new payment models on quality of diabetes care and outcomes. Curr Diab Rep. 2016;16:51.

11. Barnett JC, Berchick ER. Health Insurance Coverage in the United States: 2016. Washington DC: US Government Printing Office, Current Population Reports, 2017, pp. 60-260.

12. Glantz N, Duncan I, Ahmed T, et al. Racial and ethnic disparities in the burden and cost of diabetes for US Medicare beneficiaries, Health Equity. 2019;3:1:211-218.

13. Pugh JA, Tuley MR, Hazuda HP, et al. The influence of outpatient insurance coverage on the microvascular complications of non-insulindependent diabetes in Mexican Americans. J Diabetes Complications. 1992;6:236-241.

14. U.S. Census Bureau. QuickFacts. 2018. Available at www.census.gov/ quickfacts/fact/table/santabarbaracountycalifornia Accessed November 15, 2019.

15. Bickel G, Nord M, Price C, et al. Guide to Measuring Household Food Security, Revised 2000. Alexandria VA: U.S. Department of Agriculture, Food and Nutrition Service, 2000.

16. Health Leads. Health Leads screening toolkit. 2018. Available at www .healthleadsusa.org Accessed November 17, 2019.

17. Institute of Medicine. Capturing Social and Behavioral Domains and Measures in Electronic Health Records. Phase 2. Washington, DC: National Academies Press (US), 2015.

18. Centers for Medicare \& Medicaid Services. CMS quality strategy 2016. Available at www.cms.gov/medicare/quality-initiatives-patientassessment-instruments/qualityinitiativesgeninfo/downloads/cmsquality-strategy.pdf Accessed November 17, 2019.

19. American Diabetes Association. Brief Perceived Self-Assessment of Diabetes Management. Arlington, VA: American Diabetes Association, 2016

20. Matthews DR, Hosker JP, Rudenski AS, et al. Homeostasis model assessment: insulin resistance and beta-cell function from fasting plasma glucose and insulin concentrations in man. Diabetologia. 1985;28:412-419. 
21. Woolcott OO, Bergman RN. Relative fat mass (RFM) as a new estimator of whole-body fat percentage-a cross-sectional study in American adult individuals. Sci Rep. 2018;8:10980.

22. Kroenke K, Spitzer RL, Williams JB. The PHQ-9: validity of a brief depression severity measure. J Gen Intern Med. 2001;16:606-613.

23. Bobes J, González MP, Vallejo J, et al. Oviedo Sleep Questionnaire (OSQ): a new semi-structured Interview for sleep disorders. European Neuropsychopharmacology. 1998;8(Suppl 2):S162.

24. Paz Garcia-Portilla M, Saiz PA, Diaz-Mesa EM, et al. Psychometric performance of the Oviedo Sleep Questionnaire in patients with severe mental disorder. Rev Psiquiatr Salud Ment. 2009;2:169-177.

25. Cohen S, Kamarck T, Mermelstein R. A global measure of perceived stress. J Health Soc Behav. 1983;24:385-396.

26. Brondolo E, Kelly KP, Coakley V, et al. The Perceived Ethnic Discrimination Questionnaire: development and preliminary validation of a community version. J Appl Soc Psychol. 2005;35:335.

27. Mills SD, Malcarne VL, Fox RS, et al. Psychometric Evaluation of the Brief Acculturation Scale for Hispanics. Hisp J Behav Sci. 2014;36:164-174.

28. Lee SY, Stucky BD, Lee JY, et al. Short Assessment of Health LiteracySpanish and English: a comparable test of health literacy for Spanish and English speakers. Health Serv Res. 2010;45:1105-1120.

29. Petrie KJ, Weinman J. Patients' perceptions of their illness: the dynamo of volition in health care. Curr Dir Psychol Sci. 2012;21:60-65.

30. Sawyer AT, Harris SL, Koenig HG. Illness perception and high readmission health outcomes. Health Psychol Open. 2019;6:2055102919844504.

31. Glantz N, Larez A, Morales J, et al. Diabetes and doom: lay perceptions of diabetes stratified by biometrics in Latinos with type 2 diabetes. Diabetes. 2019;68(Suppl 1):832-P.

32. Lavange LM, Kalsbeek WD, Sorlie PD, et al. Sample design and cohort selection in the Hispanic Community Health Study/Study of Latinos. Ann Epidemiol. 2010;20:642-649.

33. Casagrande SS, Aviles-Santa L, Corsino L, et al. Hemoglobin A1C, blood pressure, and LDL-cholesterol control among Hispanic/Latino adults with diabetes: results from the Hispanic Community Health Study/Study of Latinos (HCHS/SOL). Endocrine Practice. 2017;23:1232-1253.

34. Klein S, Allison DB, Heymsfield SB, et al. Waist circumference and cardiometabolic risk. Diabetes Care. 2007;30:1647-1652.

35. Wassertheil-Smoller S, Arredondo EM, Cai JW, et al. Depression, anxiety, antidepressant use, and cardiovascular disease among Hispanic men and women of different national backgrounds: results from the Hispanic
Community Health Study/Study of Latinos (HCHS/SOL). Ann Epidemiol. 2014;24:822-830.

36. Bazargan-Hejazi S, Arroyo JS, Hsia S, et al. A racial comparison of differences between self-reported and objectively measured physical activity among US adults with diabetes. Ethn Dis. 2017;27:403-410.

37. Tudor-Locke C, Bassett DR, Jr. How many steps/day are enough? Preliminary pedometer indices for public health. Sports Med. 2004;34:1-8.

38. Bevier W, Glantz N, Hoppe C, et al. Physical activity levels among Latino adults with type 2 diabetes. Diabetes. 2019;68(Suppl 1):737-P.

39. Lopez L, Golden SH. A new era in understanding diabetes disparities among U.S. Latinos—all are not equal. Diabetes Care. 2014;37:2081-2083.

40. Seligman H, Schillinger D. Hunger and socioeconomic disparities in chronic disease. N Engl J Med. 2010;363:6-9.

41. Vargas-Bustamante A, Vilar-Compte M, Ochoa Lagunas A. Social support and chronic disease management among older adults of Mexican heritage: a U.S.-Mexico perspective. Soc Sci Med. 2018;216:107-113.

42. Strom JL, Egede LE. The impact of social support on outcomes in adult patients with type 2 diabetes: a systematic review. Curr Diab Rep. 2012; 12:769-781.

Cite this article as: Glantz NM, Morales JM, Bevier WC, Larez A, Hoppe CB, Duncan I, Mackenzie A, Kerr D (2020) Insurance status and biological and psychosocial determinants of cardiometabolic risk among Mexican-origin U.S. Hispanic/Latino adults with type 2 diabetes, Health Equity 4:1, 142-149, DOI: 10.1089/heq.2019.0119.

$\begin{aligned} & \text { Abbreviations Used } \\ & \mathrm{BMI}=\text { body mass index } \\ & \mathrm{FQHC}=\text { federally qualified health center } \\ & \mathrm{HCHS} / \mathrm{SOL}=\text { Hispanic Community Health Study/Study of Latinos } \\ & \mathrm{HOMA}-\mathrm{IR}=\text { homeostatic model assessment for insulin resistance } \\ & \mathrm{SD}=\text { standard deviation } \\ & \mathrm{SDRI}=\text { Sansum Diabetes Research Institute } \\ & \mathrm{T} 2 \mathrm{D}=\text { type } 2 \text { diabetes }\end{aligned}$

